\title{
LIV. Researches on unipolar induction, atmospheric electricity, and the aurora borealis
}

\section{E. Edlund}

To cite this article: E. Edlund (1878) LIV. Researches on unipolar induction, atmospheric electricity, and the aurora borealis , Philosophical Magazine Series 5, 6:39, 423-436, DOI: $10.1080 / 14786447808639536$

To link to this article: http://dx.doi.org/10.1080/14786447808639536

曲 Published online: 13 May 2009.

Submit your article to this journal $[\pi$

Џ Article views: 3

Q View related articles $₫$ 
This almost total absence of the elongated form arises from Clausius' fundamental hypothesis, that the motions of the molecules emitted by a stratum may be represented by radii drawn to a sphere from an excentric point; whereas it appears from the discussion in the earlier part of the present memoir that the encounters that take place within each of the two streams into which the gas may be divided, give to the surface to which the radii are to be drawn an elongated form. This omission from Clausius' hypothesis does not sensibly affect the spherical harmonics of the first order, and accordingly his hypothesis is adequate as regards the flow of heat, which depends exclusively on one of these ; but it renders the hypothesis an insufficient one as regards polarization stress, or any other phenomenon which depends on spherical harmonics of the second order.

LIV. Researches on Unipolar Induction, Atmospheric Electricity, and the Aurora Borealis. By E. EDLund, Professor of Physics at the Swedish Royal Academy of Sciences.

[Concluded from p. 371.]

A $S$ the magnetic properties of the earth cannot be fully acA counted for by assuming the existence of a magnet in its interior, it is quite evident that the preceding consideration can only indicate the general course of the phenomena in question. We will now rapidly examine whether the results of that consideration are conformable to those given by observation.

Atmospheric electricity has long been the object of repeated investigations. These have been so numerous that to give an

two square centimetres at the distance of a fourth-metre asunder and kept at temperatures that differ by $10^{\circ} \mathrm{C}$. To turn this into kinetic measure we must multiply by $41600 \times 1000000$; so that $\mathrm{G}$ would amount to about 1144000 in G.O.S. kinetic measure ( $i$. $e$. in hyper-fifth-grammetres per second). Again, we may take as rough approximations,

$$
\begin{aligned}
& \rho_{0}=\frac{1}{800}, \\
& \mathrm{~T}_{0}=\mathrm{T} . \\
& \beta^{2}=2 \cdot 6, \\
& \mathrm{P}_{0}=\mathrm{P}_{1}=1000000 .
\end{aligned}
$$

Introducing these values into equation (18), we find approximately,

$$
k=0.001
$$

of a hyper-milligram per square centimetre-an amount which, as it ought to be, is vastly smaller than that indicated by experiment. 
account of them would require too much space ; and it is besides the less necessary as we already possess a statement, followed by a very well executed critical discussion, of those observations*. Some physicists have essayed to explain the results obtained by observation by assuming that the air itself is electropositive in its normal state; while others have thought that the surface of the earth is electronegative, and that it produces by induction the electrical phenomena observed in the atmosphere. Opinions have been much divided upon the true cause of the electric state of the air or of that of the earth's surface. Some have assumed that evaporation from the sea, lakes, and the wet surface of the ground renders the atmosphere electropositive and the earth electronegative; others, on the contrary, that the distribution of electricity has its effcient cause in vegetation, in the putrefaction of organic matters at the surface of the earth, in the friction of the air against the ground or the water, or in the condensation and rarefaction of the air, \&c. More exact researches having shown that none of these opinions can be correct, the phenomenon has been attributed to a purely cosmic cause, having its seat in the empty space surrounding the earth, or in other celestial bodies, chiefly the sun. In a word, up to this hour no one has succeeded, either in consequence of observations, or by theoretic considerations, in assigning a valid and trustworthy cause for the electric phenomena of the terrestrial atmosphere. From the above-mentioned observations, however, it appears that the atmosphere, under normal conditions, can be regarded as electropositive in its lower strata (accessible to observation), that the amount of electricity increases with the height above the earth's surface, and that the amount is subject to a diurnal and an annual variation.

From the preceding exposition of the cause of unipolar induction it follows that the atmosphere must be electropositive, and the earth electronegative. The electric molecules at and beneath the earth's surface are directed by the force of terrestrial unipolar induction into the atmosphere, where they accumulate until they attain a certain density, dependent on the greater or less conductivity of the strata of air. It is only successively that, impelled by the same force, they arrive in the upper strata of the atmosphere, endowed with a high degree of conductivity, but certainly inferior to that of the metals. At the same time that the electric molecules rise above the surface of the earth, they are earried, in both hemispheres, from the lower into the higher latitudes, where the electric density

* Om den s. $k$. luftelektriciteten (Sur l'electricité atmosphérique), par H.-E. Hamberg. Lipsala, 1872. 
in consequence perpetually goes on increasing. The forces tending to conduct the electric molecules in the vertical and horizontal directions are very feeble above and around the magnetic poles; and consequently the electric density of the atmosphere attains a maximum at a certain distance from those poles. As we have seen, this maximum of electric density forms a zone enclosing, in the northern hemisphere, both the magnetic and the astronomic pole; and doubtless it is the same in the southern hemisphere. The magnetic forces act always with equal intensity, as the relatively slight variations undergone by the terrestrial magnet from one period to another can be neglected. If, then, the conductivity of the air were equally invariable, the electrical tension of the lower strata of the atmosphere would remain always the same; but as this condition is by no means fulfilled, that tension must necessarily vary. It is evident that the electric tension at a given point near the surface of the earth does not depend solely on the conductivity of the air around that point, but also on that of the higher strata, up to the height where the conductivity becomes sufficiently good in consequence of the rarefaction of the air. Suppose, for example, that a fog envelops the terrestrial surface, and that above the fog is a stratum of dry air impenetrable to electricity; the force of magnetic induction, still active, will then direct the electric molecules from the earth into the fog, which will soon show itself electropositive, as observations have proved. If, on the contrary, the fog extended up to the higher, conductive strata of the air, doubtless the electric charge of the lower strata would disappear suddenly. From this we see how hazardous it is to attribute the greater or less electric charge of the air at a given place to the greater or less humidity of the air observed at the same place. In my opinion it is highly probable that the periodic variations, both the diurnal and the annual, in the electric state of the lower strata of the air have their cause in the variations of the conductivity of the atmosphere; but certainly it is not enough to take into consideration only those variations which happen upon the spot where the observations of atmospheric electricity are made.

The electric condition of the air in the polar regions is especially interesting. Scoresby, in spite of reiterated trials, found it impossible to discover in those regions the slightest trace of electricity in the air*. The French expedition of the corvet 'La Recherche', which passed the winter of 1838-39 at Bossekop in the Altenfjord (about $70^{\circ} \mathrm{N}$. lat.), applied themselves repeatedly to the examination of the electricity of

- An Account of the Arctic Regions, vol. i. p. 382 : Edinburgh, 1820. 
the air. MM. Lottin and Bravais, who made during the summer experiments of this kind in lower latitudes, obtained positive deflections upon a straw electroscope when it was placed in metallic connexion with arrows shot into the air. Now these deflections ceased to be obtained as soon as the latitude of the North Cape was reached. In February and March, however, they several times succeeded in detecting feeble traces of positive electricity in the air on putting the electroscope in connexion with kites which they raised to a considerable height*. During the Swedish expedition to Spitzbergen in 1868, M. Lemström tried in vain to discover traces of electricity in the air $\left(80^{\circ} \mathrm{N}\right.$. lat. $) \dagger$. M. Wijkander had better luck in the expedition of 1872-73 to the same regions. Furnished with a more sensitive apparatus than those employed by his predecessors, in the autumn of 1872 he continually obtained proofs of positive electricity in the air. During the winter, from the middle of January to near the end of May, on the other hand, the electricity shown was sometimes positive, sometimes negative. In fact he obtained 20 positive and about an equal number of negative observations. The observations made in the course of the spring, when the temperature approached zero, gave the same results as the summer observations-namely, slight traces of positive electricity. It is, moreover, a remarkable fact that the air was generally positive during the winter days when aurora boreales appeared, but on other occasions most frequently negative. Respecting this the following remark is made by $\mathbf{M}$. Wijkander, which in my opinion is well worthy of consideration :- "All the observations which were made agree in this, that, in the latitudes in question, at the highest temperatures the air conducts electricity with great facility-a circumstance to which have been attributed the absence of thunder and the presence of the aurora borealis. Divers physicists have believed that this may be assumed to depend on the humidity of the air in those regions; but that other causes also contribute to it is proved by the fact that the same temperature and the same degree of humidity do not exert this action to so high a degree in lower latitudes"

These observations prove indubitably that the cause to which the positive electricity of the air in those regions is due is very feeble. It cannot, in my opinion, be attributed to the humidity and consequent conductivity of the air. If that

* Voyage en Scandinavie et en Laponie: Magnét.terr., t. iii. ; and verbal communications from M. Siljeström, who took part in this expedition.

† Översigt af Kongl. Vetenskaps-Akademiens Förhandlingar, 1869.

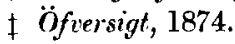


were the case, fog in lower latitudes ought only to betray insignificant traces of electricity, since the conductivity of fog is surely as good as that of the air of the polar regions under ordinary circumstances. Now we know that, notwithstanding its high conductivity, fog is very strongly electropositive.

The real cause of the above-mentioned results of observation is, in my opinion, that the vertical component of the force of induction, or, in other terms, the force tending to direct the æther (electropositive fluid) from the earth to the air, is very insignificant. The electropositive charge of the air must therefore be feeble, and sometimes so slight that the air becomes negative by communication with the earth, as is shown by M. Wijkander's observations. The earth itself, on the contrary, must always be electronegative in those regions. If no exterior force acted upon the electric fluid, the earth and the atmosphere would be in the neutral state; but as a portion of the electropositive fluid which belonged to the earth has been conveyed into the atmosphere in consequence of the action of the induction-force, the earth itself must be electronegative. The earth being a good conductor of electricity, and at the same time constituting a spheroid, its negative electricity must be distributed in a pretty equal fashion at its surface; consequently the terrestrial surface must likewise show itself electronegative in the polar regions, although the vertical component of the force of induction is there very feeble. With the exception of some rare occasions when it was difficult or impossible for him to detect traces of electricity, M. Wijkander also found that the earth was constantly electronegative. It follows also from the proposed theory that the conductivity of the air in the polar regions should, as $M$. Wijkander describes, appear greater than at lower latitudes for the same temperature and with the same humidity. If a conducting body placed in the atmosphere is charged with electricity, evidently it must be influenced by the vicinity of an electronegative body so large as the earth. If the conductive body is charged with positive electricity, this electricity is attracted downward by the negative earth; if the charge is negative, the reverse takes place, for the same reasons. Consequently, in both cases the loss of the electricity in the air is accelerated by the negative earth being in the vicinity of the charged body. Now the force of induction of the earth acts upon the electricity of the body in the opposite direction. If the body is electropositive, that force tends to direct the electricity of the body from below upwards, and vice versâ if the body is electronegative. Therefore the earth's induction-force tends to diminish the influence of the earth's electricity upon 
the charge of the body. In the regions of the terrestrial surface where the force of induction is either zero or very little, the body will in consequence more readily lose its electric charge than in the localities where that force is greater; the conductivity of the moist air will therefore uppear greater in the polar regions than at lower latitudes. The composition of pure air is, without any doubt, the same in the frigid as in the temperate zone; at the same temperature and under the same pressure it must in both regions contain, when saturated, the same quantity of aqueous vapour: and it is impossible to discover any reason for which its electric conductivity should be different. It is, therefore, to exterior causes that we must attribute the rapid loss of the charge of electrified bodies in the polar regions ; and the exterior causes are probably those which have just been indicated.

According to the proposed theory it is self evident, without any other explanation, that the air would, as was proved by the observations of M. Wijkander, exhibit traces of positive electricity on the days distinguished by intense auroræ boreales.

The cause just given for the electric state of the atmosphere is probably the only one which acts uninterruptedly everywhere; but no doubt there exist others, the action of which, connected with certain localities, is of a more accidental character. To these belong, for instance, the development of electricity described by M. K.-A. Holmgren, who found that, on the division of a liquid into drops, an electromotive force arises at the point itself where the division is effected *. To the same force is probably due the negative electricity of the fine drizzle carried away by the air in cascades or powerful cataracts. As to evaporation, vegetation, the friction of the molecules of the air against one another or against the surface of the earth, as well as several other phenomena in which some have been willing to trace the cause of the electricity of the air, they have assuredly no sensible influence upon the phenomenon in question $\dagger$. Of course, however, if clouds in the

* "De l'Électricité comme Force cosmique," par K.-A. Holmgren, Mémoires de l'Académie des Sciences, t. xi. (1872).

+ Of all those so-called causes of the electricity of the air, and of the aurora borealis, evaporation is, without doubt, that which has attracted most notice; but manifold reasons may be cited for the opinion that evaporation has nothing to do with this phenomenon. We may observe, in the first place, that no one has ever succeeded in definitively proving, by experiments made in the laboratory, that evaporation produces electricity. This opinion, therefore, is not founded on a solid basis of experiment. Further, according to this opinion the electricity of the air ought to be more intense in summer than in winter, secing that the evaporntion is 
atmosphere have been charged, in the way indicated, with positive electricity, other clouds may in turn be negatively electrified by influence.

As was said above (p. 364), the electropositive fluid (the wther) flows from the upper strata of the atmosphere to the earth in the direction of the dipping-needle. The vertical component of the induction-force in general diminishes as we remove from the equator towards the pole, while the density of the electric fluid present in the atmosphere increases with the latitude. On arriving near enough to the pole for that component and the electric resistance of the air to be no longer capable of opposing a sufficient obstacle, the positive fluid flows down into the electronegative earth. The localities where this takes place form a continuous zone surrounding, in the northern hemisphere, both the magnetic and the astronomic pole, and descending in America to lower latitudes than in the Old World. In my opinion, to the passage of these currents through the rarefied air we must ascribe the production of the aurora borealis*.

greater in the former season than in the latter. Now, as every one knows, what takes place is precisely the contrary. The positive electricity produced by evaporation, chiefly in the torrid zone, would rise into the atmosphere with the ascending aqueous rapour, would then be conducted by the upper currents of air (the counter-trades) towards higher latitudes, where it would form the aurora borealis by its descent to the earth. But these currents are at an insignificant height from the ground in comparison with that of the auroræ boreales; and, besides, they descend to the surface of the earth long before arriving at the regions marked by the principal frequency of these phenomena. Although complete confidence cannot be accorded to the measurements of the altitude of the aurora borealis, we are certain that it is sometimes very considerable. Some determinations made during the above-mentioned French expedition indicate a height of 150 kilometres; and the height has been found still greater on other occasions. (At the highest latitudes, however, the aurora borealis may from time to time appear at a short distance from the terrestrial surface, as is proved by the observations of Farquharson, Wrangel, Parry, Lemström, and several other arctic voyagers.) At so great an elevation the extremely rarefied air is assuredly not troubled by winds; and it is difficult to conceive how that rarefied air could become electric through the evaporation produced in the equatorial regions. If there existed no special force to raise the electropositive fluid into the atmosphere, this fluid must immediately descend to the earth, and the atmosphere would certainly exhibit no traces of electricity.

* On the passage of electric currents through the air M. Lemström has made some experiments which throw much light upon the phenomenon in question (Archives des Sciences Phys. et Nat. t. liv. pp. 72, 162). With the aid of a Holtz machine he kept at a determined electric charge a metal knob furnished with some metallic points. With this view the knob was connected by a conducting wire to one of the poles of the machine, while the other pole was in communication with the earth. 
It is evident, therefore, that auroræ boreales must become more numerous in proportion as we come nearer to this ring from the south, and that their greatest frequency will be under this ring itself, while they commence to decrease again in number and in brightness at still higher latitudes. Southward of the ring, the observer sees the aurora in the north; if he is beneath it, the aurora occupies, when seen under favourable circumstances, the greater part of the sky; and, lastly, if he is northward of the ring, the aurora appears on the south. It can hardly be admitted that this ring occupies an absolutely fixed position in the atmosphere; rather is it probable that on one occasion it is situated more to the south or more to the north than on another-a circumstance which may depend on the modifications of the electric conductivity of the terrestrial atmosphere. If, then, the place of the observer is at a point of the earth's surface over which the ring is usually situated, he may see the aurora borealis sometimes to the north, sometimes to the south. If this ring formed a true circle with the magnetic pole for its centre, if the intensity of the descending current were the same at every point, and consequently produced everywhere the same intensity of light, an observer on the earth to the south of the ring would necessarily see the crown of the boreal arc in the plane passing through the place of observation, the centre of the earth, and the magnetic pole. Now, if the declination-needle placed itself entirely in this plane, one would, in consequence, always perceive the summit of the boreal arc in the plane of terrestrial magnetic declination. But the ring in question does not form a perfect circle, nor can we assume that the descending currents possess everywhere the same luminous intensity. Besides, the plane in

At a certain distance from the knob some Geissler tubes were fixed to an insulated stage permitting them to be brought near to or moved away from the knob. The tubes were, as usual, furnished at their extremities with thin platinum wires. The posterior extremities were connected with the earth by a conducting wire, while the anterior extremities, or those turned towards the knob, were insulated in the air. Although there was no metallic communication between the tubes and the knob, they nevertheless commenced to be luminous as soon as the machine was put in motion, and that even when the distance between the tubes and the knob rose to 2 metres. The current which produced the luminous appearance must therefore have traversed a length of 2 metres through a stratum of air of ordinary density. It was natural that no luminosity was produced in this layer of dense air. These experiments appear to me to have much analogy with the phenomena produced on a grand scale at the formation of the aurora borealis in the terrestrial atmosphere: the electric currents coming from the upper strata descend into the earth withont producing luminous phenomena in the lowest strata of the atmosphere. 
question indicates only approximately the direction of the declination-needle. From theory, then, it follows that the direction of the declination-needle must indicate generally and approximately the summit of the boreal arc, though we are not authorized to maintain that the two must entirely coincide with one another.

In the localities on the terrestrial surface situated beneath the ring of maximum electric density the electricity descends in the direction indieated by the dipping-needle of the locality; for, as we have demonstrated above (p. 364), the action of the inductive force of the earth is equal to zero in that direction.

The descending currents cannot be compelled to deviate from the above-mentioned direction, unless, in consequence of an accidental meteorological state of the atmosphere, the electrical resistance of the air is greater in that direction than in another, in which case the intensity of the descending current will be most considerable in the direction of least resistance. As a case of this kind may easily occur, we are authorized to maintain, on the ground of the theory, only that the descending currents must be in general parallel to the dipping-needle. Now the current betrays its path through the air by a line of light. If those luminous lines parallel to one another be viewed from the surface of the earth, they will appear to converge to a point, by the same laws of perspective to which is due the visual convergence of the rows of trees of a long avenue. As to the point, it will be found in the direction which the dipping-needle at the place of observation indicates in the sky. To this optical phenomenon is due the auroral crown which appears in complete auroræ boreales. The currents in question are formed as soon as the difference of electric tension between the atmosphere and the earth is great enough to surmount the obstacle presented by the resistance of the air. Now, the earth being a good conductor of electricity, and constituting a sphere, its negative charge must be nearly the same everywhere. Doubtless no one will maintain that the positive charge of the air in the southern hemisphere is constantly equal to the same charge in the northern hemisphere. The forces which tend to render the air electropositive and the earth electronegative are equal in the two hemispheres; but the result of the activity of those forces depends in part on the meteorological state of the air, which may be different for each hemisphere. Nevertheless, as we have said, there cannot be any great difference in the negative charge of the earth; and consequently one at least of the causes on which the discharge depends is common to both hemispheres. Therefore nothing very extraordinary can be found in the fact that 
auroras are often simultaneous in the northern and the southern hemisphere.

If we compare the theoretic deductions above formulated with the results of observation, we shall find that there exists a satisfactory accordance between them.

According to Loomis, in North America, under the meridian of Washington and at the 40th parallel, 10 auroras per year are seen ; under the $42 \mathrm{nd}$ parallel the number amounts to 20 ; and near the 45 th the number is 40 . In the latitude of $50^{\circ}$, the number of auroræ boreales yearly is stated at 80 ; and between this latitude and that of $62^{\circ}$ the aurora appears nearly every night. Between the last two latitudes the aurora borealis appeared quite as often to the south as to the north. Here, then, is situated the zone, properly so called, of the auroræ boreales, of which about $56^{\circ}$ may be considered the mean latitude. To the north of $62^{\circ}$ the auroras appear almost exclusively on the south side, and they diminish in number and brightness as we advance northward. At $67^{\circ}$ lat. their number has fallen to 20 , and is only 10 in the vicinity of $78^{\circ}$. The same fact presents itself at the meridian of St. Petersburg; but here the zone of the auroras is situated much more northward than in America : it is only between the 66th and 75 th degrees of north latitude that the annual number of auroræ boreales is stated at $80^{*}$.

A multitude of measurements upon the position of the auroral are were made at Bossekop in the winter of 1838-39, by the French Expedition to Spitzbergen and Norway. The result of more than 200 measurements was, that the crown of the arc was situated $10^{\circ}$ west of the magnetic meridian. Argelander had arrived at results nearly the same by his observations made at $\AA$ bo, in Finland. In consequence of accidental circumstances, the crown of the auroral arc appeared several times to the east of the magnetic meridian. The position indicated being the mean of all the observations, is cleared of accidental perturbationst. The fact that the crown of the auroral arc must in those regions appear, on the average, to the west of the magnetic meridian flows directly from the theory, if we take into consideration the geographical situation and the magnetic declination of the locality, as well as the form and situation of the annular space of the maximum of electric density. It is easy, in the same way, to understand the accuracy of Argelander's observations. In North America, on the contrary, as in Siberia, the crown of the auroral arc must more nearly coincide, on the average, with the magnetic meridian ;

* Loomis, Annual Report of the Smithsonian Institution, 1866.

† Sur les Aurores boréales tues à Bossekop et à Juprig: Paris, 1846. 
I am not, however, acquainted with any results of observations, freed from accidental perturbations, of a nature to confirm or refute this assumption.

Wilcke* had already observed that the place of the auroral crown is in the zenith of the magnetic meridian, or in its vicinity. The correctness of his observations has been many times confirmed since then by other physicists. The abovementioned French Expedition made 43 determinations, the mean result of which was, that the situation of the crown doviates less than $1^{\circ}$ from the magnetic zenith. The difference, however, between the two positions amounted to $15^{\circ}$ on one occasion, and to $12^{\circ}$ on two others.

In explaining the annual period of frequency of the auroræ boreales shown by the observations, the following circumstances must be considered:-The electric fluid accumulated in the earth's atmosphere by the unipolar induction of the terrestrial magnet descends to the surface of the earth either by disruptive discharges (thunder-storms), or in feeble continuous currents. The former bave their principal frequency between the tropies, and the latter in high latitudes. The fluid which does not flow to the earth in the first of these two ways, is conducted by the magnetic force to higher latitudes, where it flows down in the form of continuous currents. From this it follows that the rarer and weaker the tempests, the more intense and numerous must the auroræ boreales be, and vice cersâ. In the zone of calms, immediately to the north of the equator, thunder is heard throughout the year; but the limits of this zone vary from one season to another. Outside of that zone, but between the tropics, thunder-storms travel, like the rainy seasons, with the sun. We can therefore assume that the quantity of the electric fluid which within the tropics descends to the earth in tempests is not the same all through the year. As is known, the auroræ boreales present two maxima, viz. at the spring and autumn equinoxes. According to our view the tempests would consequently be the weakest, or, rather, the least quantity of electric fluid would descend in lightning from the atmosphere to the surface of the earth, within the tropics, when the sun crosses the equinoctial line. We have not sufficient materials of observation for deciding whether this view is correct or notf.

It cannot be admitted that the electric fluid flows down upon the earth only on the occasion of auroræ boreales. Beyond all: doubt the flow is continual, although mostly the currents do

* Kongl. Vetenskaps - Akademiens Handlingar för 1777 (vol. xxxviii.).

+ It appears to follow from the observations made upon the aurura borealis by the Austro-Hungarian Arctic Expedition of 1872-1874, that

Phil. Mag. S. 5. Vol. 6. No. 39. Dec. $1878.2 \mathrm{~F}$ 
not possess the force to render the air luminous. The electric fluid is driven into the air, by forces incessantly active, from every point of the earth from the equator to the localities where the downflow is effected; and that fluid is at the same time conducted from the lower to the higher latitudes. We must therefore admit the incessant passage of currents from the equator towards the poles, while the electric fluid circulates in the opposite direction within the earth. This does not mean that the direction of these currents is entirely north and south, many causes contributing to make them deviate from that direction. We picture to ourselves the atmosphere cut by a plane parallel to the equatorial plane and situated between that plane and the auroral ring. The electric fluid driven by the active forces of the earth into the atmosphere between the equatorial plane and the plane in question must then pass through the latter. The sum of the currents passing through a plane of this kind will therefore be greater in proportion as the latitude of the plane is higher; consequently the intensity of the currents increases from the equator towards the poles. Although the electromotive forces to which these currents are due are always the same, yet their intensity must be subject to incessant variations, seeing that it of course depends also on the resistance they meet with in their course. This resistance must depend in great part on the constitution of the air in its lower strata : when these are saturated with humidity, the electric resistance is much less than when they are relatively dry. As, for this reason, these primitive currents often vary in intensity, induction currents will result, of a sort to complicate still more the system of currents we are here considering.

It is obvious that these currents must act upon a declination-needle placed at the surface of the earth; but to calculate the intensity and direction of the action is not so easy. In the first place, the currents in question act directly on the declination-needle almost in the same manner as the current which passes through the circuits of a galvanometer acts on the needle of that instrument; and, in the second place, it must be remembered that the earth contains a quantity of magnetizable materials, the magnetic condition of which is modified

the zone of maximum of auroræ boreales shifts so as to be found more northward during the winter and summer than at the periods of the autumnal and vernal equinoxes. If this be confirmed by future observations, the annual variation ascertained at lower latitudes may be accounted for by this displacement. (See Nordlichtbeobachtumgen der österveichischungarischen arktischen Expedition 1872-1874, by C. Weyprecht: Vienna, 1878. 
by these currents. All these circumstances have a marked influence upon the declination. Thus, although it may be impossible beforehand to determine exactly the action of these currents upon the declination-needle, we can compare the variations of the declination with the results given by the observations.

The relative humidity of the air is in general greater during the night than during the day. It may be taken as a rule that the diurnal variation of that humidity increases with the variation of its temperature: it is consequently greater in summer than in winter. The conductivity of the air, and, in consequence, also the intensity of the currents in question, have therefore a diurnal and an annual period. Now, if it be admitted that the diurnal variations of the declination depend chiefly on the variations in the intensity of the currents we are considering, it follows that the diurnal variations of the declination should be greater in summer than in winter, and should moreover increase with the distance from the equator-a deduction confirmed, as we know, by the observations. To this may be added that the action upon the declination-needle does not depend exclusively on the nature of the air and the intensity of the current at the locality in which the needle is placed; the intensity of the currents in localities the most distant acts also, although in a less degree. Besides, it is evident that here we have to do with the humidity of the air not merely at the surface of the earth, but also in the upper strata of the atmosphere. We ought not, then, to expect that the variations of declination at a given place will be in direct proportion to the humidity of the air at the same place.

When, for one cause or another, the current descending to the earth from the upper regions of the atmosphere has acquired sufficient intensity, it produces a luminosity in the rarefied air, aud we then have the aurora borealis. If the current is endowed with an invariable intensity (as appears to be the case in some of the feebler aurora boreales), the needle remains pretty steady; but when there are rapid variations in the intensity of the current, or when its maximum of intensity shifts from one point to another (in which case the aurora becomes sparkling and changes its aspect continually), the needle, as can be readily understood, becomes agitated and moves violently. This agitation extends over a considerable portion of the earth's surface, and thus indicates what is going on in the atmosphere, even when no aurora borealis is perceived.

The thesis that the auroræ boreales are produced by electric currents is not new; the majority of physicists have long been agreed in regard to this, with good reason. But hitherto no

$$
2 \mathrm{~F} 2
$$


one has been able to discover the true and most active cause of those currents, as well as of the electrical phenomena of the atmosphere in general. In fact there are good grounds for asserting that none of the explanations given, up to the present, of these phenomena will bear the examination of scientific criticism. If, till now, no one has seen in these phenomena the results of the unipolar induction of the earth, it is, without any doubt, because an idea has been formed of the nature of that induction which did not permit its application to this object.

There still remain many things that are obscure in the phenomena of the aurora borealis and atmospheric electricity. Of these it will be sufficient to indicate the secular periods in the frequencr of auroræ boreales. The relation of these periods with the solar spots gives positive evidence of the cooperation of extratellurian forces. The preceding statement has no claim to be presented as a complete theory of atmospheric electricity and auroræ boreales. My intention has been simply to show that the unipolar induction of the earth plays a most important and significant part in the explanation of those phenomena, and that it ought not to be neglected by those physicists who hereafter apply themselves to this matter.

\section{On a Test for Telegraph Lines. By Oliver Heaviside*.}

7 THE true conduction and insulation resistances of a uniform line may be found from the potential and current at the ends, when a constant electromotive force acts at onc end. Suppose at one end $A$ of the line there is a battery of electromotive force $\mathrm{E}$, and a galvanometer, the two together of resistance $R_{1}$; also at the other end $B$ of the line a galvanometer of resistance $R_{2}$, the circuit being completed through the earth. If the potential at distance $x$ from $\mathrm{A}$, where $x=0$, is $v$, the current at the same point $\gamma$, the conduction and insulation resistance $k$ and $i$ respectively per unit of length, then

where

$$
\frac{d^{2} v}{d x^{2}}=h^{2} v,
$$

$$
l^{2}=\frac{k}{i} ;
$$

and

$$
\gamma=-\frac{1}{h} \frac{d v}{d x} ;
$$

* Communicated by the Author. 